\title{
Research on Mental Health Education of Vocational College Students
}

\author{
Huiwen Luo \\ Sichuan Vocational and Technical College \\ Suining, Sichuan, 629000, China
}

\begin{abstract}
The mental health education of vocational college students is an important part of the ideological and political work of the vocational college, which is conducive to improving the overall quality of vocational students. However, there are many contradictions between vocational college students. To strengthen the mental health education of vocational college students, it is necessary to improve the classroom education, build excellent campus culture, carry out campus psychological counseling, and strengthen the connection with the family to achieve good results. Educators have to improve classroom teaching content, optimize the campus culture, offer reasonable and practical psychological counseling work, and strengthen the connection with students' families, so as to improve students' mental health education.
\end{abstract}

Keywords-Vocational college students, Mental health, Education

\section{INTRODUCTION}

The National Vocational Education Reform Implementation Plan (Guo Fa [2019] No. 4) pointed out: "To be guided by Xi Jinping's new era of socialism with Chinese characteristics, we need to put vocational education in a more prominent position in education reform and innovation and economic and social development." [1]. In his 2019 government work report, Premier Li Keqiang pointed out: "We need to accelerate the development of modern vocational education, reform and improve the examination and admission methods for vocational college, and expand enrollment of 1 million people this year." [2].

The Communist Party of China and the state attach great importance to the expectations of the society, asking for higher requirements for vocational college education. Vocational college should adhere to the fundamental task of strengthening moral education and cultivating people, constantly to strengthen the reform of education and teaching, and adhere to the teaching of students in accordance with their aptitude, and improve the quality of cultivating higher education talents in all-around way. As a large and special group, their mental health can't be ignored. It is directly associated with success in students' career and social harmony in society. The mental health of vocational college students is a issue that must be highly valued and needed to be solved urgently.

\section{The Significance OF StRengthening the MentaL HEALTH EDUCATION OF VOCATIONAL COLLEGE STUDENTS}

A. Mental health education for vocational college students is an important part of ideological and political education in the vocational college

Mental health education for vocational college students is one of the important contents of service and education, and an indispensable part of ideological and political education for vocational college students. Under the influence of economic and cultural diversification, for the moment vocational college students are facing the pressure of study, employment, communication and other aspects, prone to psychological problems. Vocational college should strengthen the mental health education of vocational college students by establishing psychological counseling institutions, setting up professional psychological counseling teachers, and offering psychological health education courses. Timely provide advice and help on problems encountered in the life of vocational college students, And answer about the higher vocational students in learning, living, employment, etc., can guide the students to form healthy personality structure, avoid them because of confused and produce negative emotions, and psychological problems. And answer relevant questions about vocational college students' problems in the study, life, employment, etc. can guide them to form a healthy personality structure and avoid their negative emotions and psychological problems caused by confusion.

\section{B. Conducive to improving the overall quality of vocational college students}

Strengthening the mental health education of vocational students is conducive to improving the overall quality of vocational students. Mental health is an important part of the overall quality of college students and the basis for the formation and cultivation of other qualities. Mental health includes not only the quality of the psychological quality, but also the quality of the mental outlook, the strength of the emotional control, and the elegance of the temperament. Strengthening the mental health education of vocational students is conducive to the establishment of correct values and the establishment of a correct world outlook, outlook on life, values, and the cultivation of a better psychological literacy, which can calmly respond to any situation. In particular, in the face of setbacks and difficulties, they can move forward without fear. 


\section{THE PSYCHOLOGICAL CONTRADICTION BETWEEN VOCATIONAL COLLEGE STUDENTS}

Generally speaking, the psychological state of higher vocational students is good, but there are also many contradictions in the higher vocational students.

\section{A. Coexistence of inferiority complex and self-esteem}

At present, most of the vocational college students are at home are spoiled by their parents, grandparents, can't accept criticism. On the one hand, they are deeply influenced by the Internet. They think that teachers and parents' education and guidance are backward; their theories are out of date and cannot keep up with the trend. They think that their ideas are very unique, no one can understand themselves, just give themselves a chance to play completely on their own can be successful, go to the top of life. On the other hand, influenced by Chinese traditional cognition, students with good grades are not willing to choose a vocational college. Therefore, most of the students study in vocational college experience academic frustration in the middle school stage, and thus have been criticized or even denied by parents and teachers. As a result, some vocational college students feel extremely inferior in their studies, deny themselves, believing that they are really not good at learning and get along with their studies. In fact, the results of conversations with students who addicted in the Internet and thought they were not good at learning at all showed that most of them had good academic performance in the early middle school. Later, due to the influence of the outside world, they gradually came into contact with online games. Since then, things have gone from bad to worse. They couldn't control themselves, and they academic declined. Subject to rejection from many parties; they continued to seek pride, achievement, identity and satisfaction in the online world, forming a vicious circle.

\section{B. Coexistence of activeness in the virtual world and closure to real world}

Since the advent of the media era, making friends, playing games, communication, understanding of news, and learning have broken through the limitations of time and space. People can study, shopping, entertain and make friends at anytime and anywhere. This originally greatly facilitated and enriched human life. However, technology is a double-edged sword, convenient and powerful mobile terminal, behind the great convenience of life also brings vocational college students in the real society closed. Vocational college students are very active in the online world, making friends, news comments, discussions and exchanges are very comfortable, but in the real society, they appear to be relatively closed. In the real world, most vocational college students' friends are limited to a few classmates in their dormitory, and they don't have much communication with classmates in class and school, and they only say hello to their parents in daily life. Due to lacking of deepgoing communications with parents, they believe that both teachers and parents can only preach. There are big gaps among them, which leads to them to feel misunderstood and isolated.In the work, it is easier to be self-centered, regardless of the feelings of colleagues around. If you felt you'd been wronged, you might think that the world has abandoned you. If you are frustrated, you may think that someone deliberately targets you and be likely to enter into psychological misunderstandings, which may lead to some psychological problems.

\section{The desire for identity and negative slack coexist}

Everyone wants to be recognized by friends and relatives around them. Higher vocational students it's exceptional also. "They have a heroic dream in their hearts. They heard stories of many people becoming famous overnight. They only saw those famous people and great people, the glory of the heroes who became famous overnight. But they ignored the efforts they made before they became famous overnight. They always dreamed that they could "catch the big luck" and met an opportunity to meet a Bole who appreciated themselves but are not willing to take the time to change oneself, adjust one's own state, accumulate one's own knowledge, exercise their own abilities. They always spend a lot of time on entertainment, making friends, games, consuming their own youth in vain; quality ability is not obtained fundamental improvement.

\section{Coexistence of cognitive development and inadequate in actions}

The vast majority of vocational college students have a clear concept of right and wrong. They all have patriotic sentiments, support the party's leadership, stand firm in the face of major issues, and have a clear understanding of right and wrong. But they are giants of thought and dwarfs of action, the disconnect between knowledge and action, and do not regard traditional morality and social norms as their own code of conduct. In the case of external supervision, they can temporarily and strictly demand themselves, lack of selfdiscipline. Be severe to others, but lenient to themselves; treat others and themselves with double standards; to lack calm thinking when dealing with things, often acting on impulse, regardless of consequences.

\section{WAYS TO StRENGTHEN THE MENTAL HeALTH EDUCATION OF VOCATIONAL STUDENTS}

\section{A. Strengthening classroom education}

Teaching is the central task of school work. The mental health education for students can't lose this main position and main channel. The first is to set up a compulsory course for mental health education, to cultivate and enhance the mental health awareness of college students, to popularize mental health knowledge and the rules of psychological activities, to help students correctly understand psychological phenomena and guide them to pay attention to mental health, popularizing methods for maintaining mental health, methods for improving psychological adaptability, and methods for relieving stress enable students to consciously conduct self-psychological adjustments in a scientific way. The second is to play an active guiding role in the subject curriculum. Any discipline has its own educational function. The student's good, positive, and progressive mental state of health can't be based on only a few mental health courses, several mental health education teachers, and several class teachers and counselors. Education is the task of all faculty and staff, including students. The guidance of a 
good psychological state is also what every teacher should do. When teaching in class, teachers should consciously introduce positive guidance to students in combination with their own courses, bring positive thinking, stimulate students' enthusiasm, enhance students' self-confidence and pride in their choice of career, and correct students' some bad ideas, exert a subtle influence on the students.

\section{B. Building an excellent campus culture}

Guide students to build a positive attitude, activate students motivation and ignite students' passion, which can be carried out by letting students recognize themselves, their major, their school, their hometown and their motherland. One is to let students recognize themselves through campus activities. Since most students have experienced setbacks in their studies, they have imposed restrictions on themselves. Many things think that they are "no good", they are unwilling, afraid to show themselves before the crowd, and they are not confident. Through a variety of healthy and active campus activities, students can re-recognize themselves, examine themselves, find their other side, and regain their confidence. The second is to interpret the school motto, spirit, and school songs, so that students have an understanding of the school's history, current situation, and development planning, and increase students' sense of identity and pride in the school. The third is to involve students in society through social practice activities, such as social surveys, support for the elderly, community services, study practice, popular science propaganda, visits to the museum and other activities. Let students see the society from different angles, experience life, correctly understand the society, know themselves, find their own accurate positioning, establish the correct value concept.

\section{Conducting campus psychological counseling}

Each college has set up a psychological counseling room. It hopes that through effective psychological counseling services, students who ask for help can alleviate psychological pressure and alleviate psychological contradictions. However, at present, there is a lack of correct understanding and understanding of psychological counseling activities among vocational college students, and the search for psychological counseling services is regarded as a disgraceful thing, and there is no courage to enter a psychological counseling institution. Therefore, the school counseling room should not wait for students to come to serve them, but should focus on the needs of different student groups and focus on building different psychological counseling system training, for example, how to adapt to the problems of freshmen's prevailing university life, how to deal with interpersonal relationships, the employment, career choice, and further education of graduate students. In view of the different psychological problems in each age group, we insist on the combination of professional counseling and counseling and strengthen psychological counseling for students in career planning and career development counseling, learning problems and academic development counseling, mental health and quality development counseling [3]. Thereby, it promotes the healthy development of college students' psychology.

In addition, an online psychological counseling platform can be constructed. On the one hand, students who are embarrassed to consult in the counseling room can have access to help, and another aspect is to take advantage of college students' interest in the Internet and take advantage of network technology. The first is to set up a mental health education course on the website, put psychological knowledge, psychological tests, psychological teaching videos and so on the Internet, so that students can have a correct understanding of psychological counseling through online learning, and have a strong interest in psychology to participate in online psychological counseling. The second is to set up an online psychological counseling public number, etc., to establish another psychological defense line for students. The third is to establish a safeguard mechanism to ensure the safety, purity, scientific and practical effectiveness of online psychological counseling [4]. Someone is put in charge of the entire supervision of online psychological counseling; strictly controlling the process of counseling is legal, moral, and institutional. He should filter out some unsuitable comments and guide the online speech properly, maintaining a strong defense against some defamation of psychological counseling and pseudo-scientific remarks. Psychological counseling should ensure the function of serving students.

\section{Strengthening contact with the family}

The mental health of students is affected by many aspects. Family factors are a factor that students cannot ignore in their mental health education management. Whether the relationship between students and family is harmonious, and whether parents' education is correct or not will affect the mental health of students. In the daily student education management work, in addition to strengthening daily guidance, education management, and continuous attention for the students with psychological problems, the education administrators need to establish contact with the parents of the students. On the one hand, they should seek support from parents and let the parents participate together. In the mental health education of students, we will consolidate the results of mental health education. On the other hand, we will guide and educate parents, let parents know the importance of strengthening students' psychological care, spread some mental health education concepts and knowledge, and play high vocational education to realize college social service functions.

\section{CONCLUSION}

At present, mental health has become a social issue, and people's understanding and understanding of it has also deepened. Strengthening psychological construction has become a social consensus. Vocational college should also continuously emphasize the importance of mental health work for vocational college students, analyze and study the mental health of vocational college students, strengthen mental health education, and enable vocational college students to become useful talents with mental health and high comprehensive quality.

\section{ACKNOWLEDGMENT}

This paper is the research result of "Innovative Research on Student Education Management in Higher Vocational College" (Project No. 2015R07). 


\section{REFERENCE}

11] Notice of the State Council on Printing and Distributing the Implementation Plan for the Reform of National Vocational Education. Guofa [2019] No. 4. [2019-5-13].

Http://www.gov.cn/zhengce/content/2019-02/13/content_5365341.htm.

[2] "Government Work Report". [2019-5-13].

Http://www.gov.cn/premier/2019-03/16/content_5374314.htm.
[3] Liu Kuanneng, Strengthening College Students' Mental Health Education, China Metallurgical Education, pp. 64-66, 2008.

[4] Wang Xiaofeng, Jiang Qiaoling, Analysis of the Service Forms of Network Psychological Counseling in Colleges and Universities, Education and Teaching Research, pp. 28-31, 2011. 